\author{
Роландас Крегждис \\ Институт литовского языка \\ Вильнюс
}

\title{
ЭТИМОЛОГИЯ РУССКОГО ДИАЛЕКТНОГО СЛОВА АНЧУТКА
}

В 1973 г. была опубликована статья Владимира Николаевича Топорова [1973: 29-44] под названием Из истории балто-славянских языковых связей: анчýmка, в которой от части разбирается мифологический ${ }^{1}$ образ этого божка и проблема этимологизации имени, которое в диалектах русского языка может обозначать 1. 'чёрт, дьявол, бес; антихрист' (Орёл, Симбирск, Тула, Рязань, Терь, терит. реки Дона, Тверь, Пенза, Курск, Тамбов, Тобол), [также выделяются альтернативные семемы того же самого референта] 1.a. 'чертёнок, бесёнок' (Саратов, Пенза, Рязань), 1.б. 'водяной чёрт' (Терь, Тамбов), 1.в. 'домовой’ (Орёл, Тамбов), 1.г. 'леший’ (Калуга); 2. 'неряха, грязнуля' (Курск, Орёл, Рязань, Калуга, Оренбург); 3. 'бедный, несчастный человек' (Курск), 4. 'баловень, баловник' (Калуга), 5. семема уничижительного значения - ругательство (Рязань, Тула, Терь, Воронеж, Тифлисская губерния) [СРНГ I 262-263]. Главный вывод, к которому приходит Топоров в конце анализа данной мифологемы, соотносим с проблематикой балто-славянских отношений, которой учёный посвятил бо́льшую часть своей научной деятельности. Он выдвинул гипотезу об употреблении балтизма на территории России (на основании этого утверждения, устанавливаются границы проживания протобалтийских племён [см. Топоров 1973: 38-41]), соотнёс русс. диал. анчу́тка с лит. диал. ančiúté, ančiùkas 'небольшая утка' [Топоров 1973: 36]. Эту гипотезу он повторил в Словаре прусского языка [Топоров 1975: 96] и, делая ту же самую предпосылку - в Мифологическом словаре [MC 54], т.е. Топоров не сомневался в существовании возможной генетической связи между русс. диал. анчи́mка и лексическими соответствиями литовского языка. Данное предположение,

\footnotetext{
${ }^{1}$ Мифологический анализ данного божка в этой статье ограничен лишь упоминанием нескольких мотивов из русского фольклора.
} 
правда, с некоторой осторожностью, повторяется и в новейших исследованиях по русской мифологии и фольклористике [см. Власова 2008: 22-23].

Лингвистическая интерпретация данного слова, которую в выше упомянутой статье представил Топоров, является весьма сложной из-за своей многогранности и, по всей видимости, нуждается в радикальной коррекции.

В начале анализа Топоров [1973: 34] настаивает на том, что русс. диал. анчýmка представляет собой производное слово с суфф. русс. -утка, с которым якобы образуются названия мелких животных (кошки, курицы и др.); при этом упоминается важная особенность семантического плана - по его мнению, таким словам часто присуще уничижительное значение (!). Основываясь на таких суждениях, автор гипотезы приходит к выводу, что анализируемым теонимом именовалось мифологическое существо маленького роста [Топоров т.ж.]. Приходится сожалеть о том, что данное утверждение не иллюстрируется соответствующими примерами русского языка, поэту судить о корректности такой гипотезы весьма трудно ${ }^{2}-$ конечно, доказательством правильности такого суждения могла бы быть семема 1.a. 'чертёнок' (Саратов, Пенза, Рязань), т.е. 'маленький чёртик' ↔ 'чёрт, дьявол, бес; антихрист' (Орёл, Симбирск и др.), или русс. диал. аню́тка 'небольшая рыбка, побольше вершка' [СРНГ I 263], но им не свойственно уничижительное значение.

Основываясь на лексическом материале русского языка, можно с уверенностью утверждать, что суфф. русс. -утка не всегда употребляется для выражения диминутивной семантической функции, кроме того с ним образуются названия животных, более крупных, чем кошка и курица, ср. русс. диал. козутка 'коза' (Псков) [ПОС XIV 329] < русс. коза + суфф. - $\boldsymbol{y} \boldsymbol{m}-$ и -ка [Горячева 2007: 39].

Коротко представив анализ морфологической структуры слова, Топоров [1973 т.ж.] переходит к этимологической описи лексемы, указав, что её необходимо начать с обсуждения лексических соответствий, которые „<..> несомненно, связаны с анчи́mка, но по сравнению с анчу́тка сохраняют ещё один элемент (-бал-, -бил-, -бул- и под.) <...>”. Необходимо обратить внимание на то обстоятельство, что автор гипотезы [Топоров т.ж.] особенно подчёркивает важность такого сравнения для установления истинного происхождения анализируемого слова, поскольку оно „<..> как раз и даёт возможность для окончательного решения вопроса". Такими лексическими соответствиями, по утверждению Топорова, являются: русс. диал. анчи́бал 'болотный чёрт, водяной; дьявол, сатана; бранное слово, басурман' (терит. реки Дона, Орлов) [СРНГ I 262], анчи́бил 'т.ж.' (терит. реки Дона, Орлов) [СРНГ т.ж.], анцьь́ба́л, аниьь́бу́л 'т.ж.' (Владимир, Курск, Псков) [СРНГ I 261-262], ании́балка, анчи́болит

2 Такие данные отсутствуют и в словаре Владимира Даля [Даль II 182-183; 223-225], и в Словаре русских народных говоров [СРНГ XV 149-151, 158; XVI 147]. 
‘бранное слово' (терит. реки Дона) [СРНГ I 262]; укр. анци́болит, анцииболо́тник, анцииболо́тський и др. Первичным значением этих слов, по мнению Топорова, является семема 'болотный чёрт, водяной', поскольку такую рефлектируют новообразования, образованны по принципу народной этимологии, ср. укр. анци-болот, анци́-болотник русс. боло́тник, укр. болотяни́к 'чорт, живущий на болоте'). Правда, свою гипотезу Топоров [1973: 36] сразу же как бы и опровергает, констатируя факт, что укр. анци́болот, анци́болотник „<...> не выглядят как старые слова”, поскольку более архаичную морфологическую структуру лексем рефлектируют русс. анчи́бал, анцб́бал, которые как раз и являются первичной основой, на базе которой могли возникнуть уже упомянутые новообразования со вторым компонентом композита, возводимым к русс. болото 'Sumpf'.

Установив такую череду морфологических изменений, автор анализа предъявляет ещё одну гипотезу - „В таком случае русск. анчи́бал точно соответствует лит. ánčiabalis 'утиное болото' <...> [Топоров т.ж.], т.е. оно возводимо к лит. ántis 'домашняя или дикая птица водяного пространства (Anas)' J, K, SD79, R, Pn, I, J.Jabl, T.Ivan, V.Krèv, Jnšk, Rs, Vlkv, BM 411, Sml, Grž, NS 97, Pn, NS 229, BsP III 30, 106, Dkš, Trgn, В [LKŽe] и лит. balà ‘болото’. Данное утверждение ${ }^{3}$ к сожалению, нуждается в существенной корректировке, поскольку русс. анчи́бал 'болотный чёрт, водяной' [СРНГ I 261-262] и лит. ánčiabalis ‘болото, в котором находятся утки' Vrn, Kb [LKŽe] по своему происхождению представляют совершенно разные лексические единицы.

Видимо, для аргументации своей гипотезы о происхождении русс. диал. анчýmка Топоров по принципам семиотического анализа создаёт лингвомифологическую модель, главной чертой которой является смысловая цепь: божество водяной среды ↔ его гидронимная локализация (см. 3 сноску). Отсутствие аналогичных типологических примеров на базе данных литовского языка, которые подтвердили бы правильность такого предположения, является веской причиной для пересмотра этимологии русс. диал. анчи́бал.

Топоров в начале разбора данной проблемы упоминает об очень важной семантической [да и акцентологической] связи между русс. диал. анчи́бал, анчи́бил, анць́бба́л, анцььббу́л и др. 'болотный чёрт, водяной и др.' [СРНГ I 261262] и русс. анти́христ, русс. диал. анчи́христ, аншиххрист 'чёрт; половина беса' [СРНГ I 262-263]. В связи с этим, можно сделать осторожное предположение о том, что русс. диал. анчи́бал является композитом [гибридом

${ }^{3}$ Подтверждение возможности таково неординарного сравнения Топоров [1973: 36] видит в детерминативной смысловой связи между (I) лит. ánčiabalis и (II) pycc. анчúбал как (I) locus $\leftrightarrow$ (II) subjectus. Самый большой недостаток такой интерпретации - сложность её доказуемости. Для верификации такого предположения необходимы примеры адекватного словообразовательного типа, которые в статье Топорова отсутствуют. Их автор гипотезы, несомненно, предъявил бы, но по причине отсутствия таковых в литовском языке, это не представляется возможным. 
из-за присутствия в структуре слова составных компонентов разных языков], рефлектирующим семантический и от части морфологический эквивалент русс. анти́христ: греч. ’́viі́- 'против' + ивр. Baal 'господь (владыка) (т.е. общеупотребительное имя божества); владелец, управляющий' [LE II 13; MC 88], т.е. определяет восстановление наименования антипода Господа // Бога.

Правильность такого суждения легко доказуема - оно подтверждается происхождением второго компонента композита русс. диал. анщ,и́б́́л, соот-

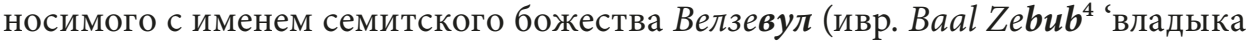
мyх' [см. RŽ 62, MC 121]), Веелзевул 'властелин демонов и зльх духов филистинян', т.е. с гипокористическим сокращением -бул от евр. Zевиb $\leftrightarrow$ (геленизированная, а потом и латинизированная форма - см. 4 сноску) лат. Zābu(a//o) lus 'дьявол, чёрт' [Niermeyer 1976: 1138]. Важнейшим фактом, подтверждаю-

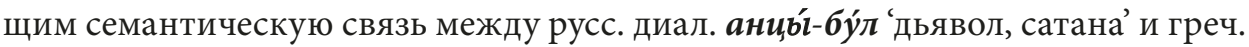
(позд.) Záßо入ос 'т.ж.', лат. zäbŏlus // zäbŭlus 'diabolus', и соответственно ивр. Baal Zebub, является рассказ авторов Нового Завета, что этим именем собственным фарисеи и книжники называли Иисуса Христа, поскольку они утверждали, что тот изгоняет бесов силою 'князя бесов', т.е. Вельзевула (Матф. 10, 25; 12, 24, 27; Мк. 3, 22; Лук. 11, 15-19) [подробнее см. MC т.ж.; LE II 14]. Значит, второй компонент композита русс. диал. анци́бб́́л должен изъясняться ни как рефлексия лит. balà 'болото', но как сокращение имени семитского бога Баал Зебуба[-була], структурно и семантически идентичного русс. анти́христ, поскольку означает имя того же самого божества.

После не совсем удачной попытки объединить в одно лексико-семантическое гнездо русс. диал. анчи́бал, анчи́бил, анцьь́ба́л, анць́ббу́л (и др.) и русс. диал. анчýmка, Топоров [1973: 36] приводит главный аргумент для пересмотра его же гипотезы насчёт этимологии этого слова - методику выделения структурных единиц слова и установления их разделительных границ: прежде истолкованная как производная форма с суфф. русс. -утка [Топоров 1973: 34], лексема почему-то заново интерпретируется как контаминационное суффиксальное образование из двух лексических единиц литовского языка: лит. диал. ančiúté ‘уточка' LKG I 282; 'пирожок в форме утки' Rdm [LKŽe] и лит. ančiùkas ‘выводок утки’ Prn, Kp, Mš, Gs, Ėr [LKŽe], т.e. суфф. лит. -ūt- + суфф. лит. -uk- > -utk-. К сожалению, автор гипотезы опять-таки не приводит ни одного примера аналогичного структурного образования литовского языка (!!!).

4 Изменение конца основы данной формы -б /в/- в -л- обусловлено греч. (позд. - Визан-

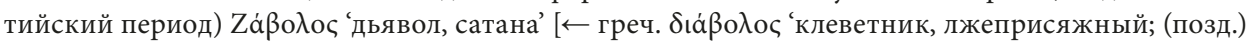
дьявол'], определившего возникновение лат. zābŏlus // zābŭlus 'diabolus' [Lewis, Short 1958: 2018 ].

5 Ивр. Baal $\leftrightarrow$ арам. Beel [LE II 13].

6 Очень редкое употребление данного слова в диалектах литовского языка (в LKŽе указывается лишь один пункт южных аукштайтов) является довольно веской причиной сомневаться в правильности такой догадки. 
Видимо, по причине неправдоподобности такого объяснения, Топоров [1973: 37] делает ещё одну попытку истолковать структуру русс. диал. анчу́тка - слово трактуется как тавтологическое образование, т.е. лит. диал. апс̌- 'утёнок' ( $\leftarrow$ лит. ančiõ kas 'выводок утки') + русс. утка 'Ente'. Такое суждение было бы приемлемо лишь в случае приведения сообразных примеров, которые в тексте статьи отсутствуют.

Попытка Топорова [1973 т.ж.] обосновать свою гипотезу балтизма, приводя аргументы внешнего облика божества - оно рогатое, беспятое, т.е. такое же, как и утка - тоже не увенчалась успехом, поскольку сам автор предположения признаёт тот факт, что все эти черты de origine свойственны чёрту. В русском фольклоре чёрт представляется также и как существо с гусиными ногами [Власова 2008: 533] [происхождение этого мотива можно объяснить средой обитания беса: озером, трясиной, водоворотом и даже морем [ср. Власова 2008: 533], т.е. той же самой средой, где обычно и живёт это пернатое]. Главный аргумент, на который опирается автор гипотезы, тот, что описываемый мифологический персонаж, как и утка, может летать, тоже является казуистическим по той же простой причине, что эта особенность свойственна и чёрту - он часто представлялся как крылатое божество [Власова 2008: 533-534], ср. чёрт иногда „летит змеем” [Власова 2008: 545]; может нестись как вихрь или бурный ветер (чёрт-вихрь) [Власова 2008: 543].

Возвращаясь к проблематике морфологического анализа и этимологизации русс. диал. анчи́тка, нужно отметить весьма важное обстоятельство лингвистического разбора данного лексико-семантического гнезда - определение базовой и производной форм. Видимо, анализ этой группы слов нужно было начать именно с базовой или производящей формы, т.е. с русс. диал. aнчým 'чёрт' (Калуга) [СРНГ I 262], а не суффиксальной производной русс. диал. анчýmка [ещё ср. русс. бу́ка 'мнимое пугало, коим разумные воспитатели стращаютъ дътей; нелюдимъ, медвъдь, человекъ неприступный, суровый, угрюмый' $\rightarrow$ русс. буканъ 'человек, на буку похожий; чёрт' [Даль I 138; СРНГ III 262] $\rightarrow$ русс. бука́нка 'фантастическое существо, живущее в доме; домовой; неаккуратная женщина' [СРНГ III 262]. Очевидно, которая из них является первичной, ср. русс. уга́dъ $\rightarrow$ угадка 'угадывание' [Даль IV 465]. Несуффиксальная и соответственно первичная форма русс. диал. анчи́m своей деривационной моделью совсем не отличается от других лексем того же самого типа, т.е. девербативов русского языка. Имея в виду возможное присутствие феномена табу при формировании морфологической структуры слова, ср. $\mathrm{He}$ ругайся на ночь, анчутка приснится; Анчу́тик садится на ноги тому, кто за столом болтает ногами во время еды [СРНГ I 262; Топоров 1973: 38-39]; ещё ср. Слово чёрт произносить грех, не то он привяжется и будет причинять зло (Вологда); Многие сло́ва чёрт не произносят, боясь чёрта, а называют его чёрный, немытик (Новгород) [Власова 2008: 535], можно сделать осторожное предположение о произошедшей морфотактической транспозиции данной 
формы - такое суждение можно аргументировать присутствием соответственных изменений в структуре названий других русских мифологических персонажей (см. дальше): русс. диал. анчу́m 'чёрт' < *анчуд 'т.ж.' [морфологическая запись; ещё ср. спорадическое изменение $-\partial-\leftrightarrow-m-:$ русс. чудо́къ $\leftrightarrow$ чуто́къ 'немножко, сколько-нибудь; косушка вина' [Даль IV 613]] русс. диал. анчию́ 'т.ж.' [Топоров 1973: 31] [с изменением -y- в -ию- из-за поздней контаминации с русс. иуда (диал. июда, ср. сл. Июда [Фасмер II 145]; ещё см. Черкасов, Москвитина 2005: 192) 'изменник, предатель’ [ср. Даль II 68] русс. Иу́da „один из двенадцати апостолов, предавший Иисуса Христа”] < русс. диал. *начуд 'т.ж.' (морфотактическая транспозиция из-за табу, ср. русс. диал. удага́нка 'ведьма' (Колыма) [см. Власова 2008: 499] < *угаданка $\leftarrow$ гл. русс. угадывать 'от(раз-) гадать, догадаться; узнать по тёмным признакам и др.' [Даль IV 464-465]7)

7 Тут необходимо отметить, что изъяснение происхождения этого слова, представленное Александром Аникиным [2000: 580], является примером народной этимологии (множество таких примеров представлено в книге Платона Лукашевича [1847]), поскольку причислив данное слово к заимствованиям из якут. удаган 'шаманка, ведьма, колдунья', а последний из монг. удаган 'шаманка', автор гипотезы забыл установить: І. источник заимствования (!!!), так как тюрк. *iduk 'свящённый’, по мнению Аникина, являющийся субстратной формой, казуистична не только из-за статуса реконструированной формы (своё суждение Аникин аргументирует лишь астериксом (!!!); кстати, такое заимствование не указано в своде тюркизмов русского языка [см. Шипова 1976: 342-343]), но и несоответствия морфофонетической структуры заимствования; II. звено морфологических изменений - неясно, (а) почему якут. удаган 'шаманка, ведьма, колдунья', семантически реализуемый как референт женского рода, в русском языке употребляется с суфф. -ка; (б) если это связанно с контаминацией русс. диал. (заим.) шаманка 'ругательство; ругательное слово' [Фасмер IV: 401; Аникин 2000: 688], тогда возникает вопрос, как в русском диалекте Сибири могло появиться заимствование, своей морфологической структурой несоответствующий морфотактической структуры русского языка, когда в этом восточнославянском языке и в его сибирском диалекте широко распространено употребление другого заимствования того же самого значения, ср. русс. шама́нъ, шама́нка 'родъ обмащиковъ, у дикихъ сибирскихъ народовъ, которые подъ видомъ колдовства обманываютъ народъ' [САР 850], шама́н, шама́нка 'служитель культа духов, вступающий в ритуальное общение с ними; колдун, знахарь, способный приводить себя в состояние экстаза' [БТСРЯ 1489], т.е. „гипотеза” Аникина искажает общепринятые теоретические основы появления суперстатной лексики: заимствование - „обращение к лексическому фонду других языков для выражения новых понятий, дальнейшей дифференциации уже имеющихся и обозначения неизвестных прежде предметов (нередко сами эти понятия и предметы становятся известными носителям данного языка лишь вследствие контактов с теми народами, из чьих языков заимствуются соответствующие слова)." [Ахманова 1969: 150-151] // “Adoption of a linguistic expression from one language into another language, usually when no term exists for the new object, concept, or state of affairs." [Bussmann 2006: 139].

Особенно настораживает одна черта этимологической описи слов, представленной Аникиным - полное отсутствие синхронного анализа лексической единицы. Он не анализирует и не детализирует особенностей изменений структурных строений лексем русского языка, но сразу берётся за реконструкцию праформ не И-Е языков (которые, по-видимому, никогда не существовали - см. дальше), хотя девербативное происхождение русс. диал. удага́нка 'ведьма (ругательное слово)' очевидно, к тому же необходимо констатировать противоположный путь 
$\leftarrow$ гл. русс. начуди́mь (начуде́сumь, начудотво́рить) 'напроказить, наделать шалостей; дивить странными распорядками и управленьемъ'8 [Даль II 497], ср. русс. диал. на́слух 'слух' (Оренбург) [Даль II 471; СРНГ ХІІ 172] Ł гл. русс. наслу́шать, наслу́шивать 'послушивать, подстерегать ухомъ и др.' [Даль т.ж.].

Возможен и другой путь объяснения образования русс. диал. aнчým слово, по всей вероятности, рефлектирует перестановку [обусловленную феноменом табу] морфологической структуры субстантива со спорадически употребляемым префиксом на-, т.е. преф. русс. на- + субст. русс. чýдо 9 'всякое явление, кое мы не умъемъ объяснить, по известным нам законам природы; диво, необычайная вещь или явление' [Даль IV 612] ↔ (?) 'чёрт’ (ср. Чудо морское, диво польское, страхъ водяной [Даль т.ж.]), т.е. можно реконструировать русс. диал. *начуд, ср. русс. диал. намолодеи ↔ молодеи 'молодой человек (при вежливом обращении)' (Владимир) [СРНГ XII 40], русс. диал. напра́вда ↔ правда 'настоящая правда' (Владимир) [СРНГ ХІІ 95], русс. диал. нарове́сница $\leftrightarrow$ ровеснииа 'сверстница' (Архангельск) [СРНГ ХІІ 126], русс. диал. насарай $\leftrightarrow$ сарай 'сеновал, навес' (Пермь) [СРНГ ХІІ 151], русс. диал. насно́ва $\leftrightarrow$ основа 'фундамент, Grundlage' (Вологда) [СРНГ XII 178], русс. диал. научи́mель ↔

заимствования выше указанных лексем, т.е. якут. удаган 'шаманка, ведьма, колдунья', монг. удаган 'шаманка' являются славянскими заимствованиями, а не наоборот, как эту довольно несложную проблему объясняет Аникин: русс. диал. гад 'отгадчик, прорицатель' Олонецкая губерн. (1846 г.), Вологда, Ярославль, Кострома, Пермь, Западная Россия; 'догадливый, хорошо угадывающий что-либо человек’ Ярославль (1853 г.); ‘знахарь’ Вологда, Пермь [СРНГ VI 90], русс. диал. гадв 'знахарь; ворожея' Западная Россия [Даль I 339] $\longleftarrow$ русс. диал. *гадан 'т.ж.' (с апокопой суфф. -ан из-за контаминации с русс. гад ‘змея’ [СРНГ VI 89] - термином сакральной сферы (!!!) [ (идентичные модели морфологической структуры nomina agentia) русс. молчанъ 'собака, которая кусаетъ молча, изподтишка, безъ лаю и др.' [ $\leftarrow$ гл. русс. молчать 'ни́шнуть, безмолвствовать, тихнуть и др.'] [Даль II 343] (больше примеров см. Зализняк 1980: 494-496)] ↔ русс. гада́нка 'гадалка' Урал 1963 г. [СРНГ VI 90]. Игнорирование структурных изменений слова привело к тому, что разные по своему происхождению и морфологическому строению омофоны русс. гад 'змея’ и русс. диал. гад 'отгадчик, прорицатель и др.' были соотнесены в одно лексико-семантическое гнездо [СРНГ VI 89-90].

Основываясь на результатах данного анализа, можно выдвинуть предположение о том, что русс. диал. удага́нка 'ведьма (ругательное слово)' должна разъясняться как девербативная русская лексема (см. выше), а не заимствование. И, напротив, в указанных азиатских языках она была заимствована для обозначения референтных семем 'шаманка, ведьма, колдунья’. Главным аргументом для восстановления русс. *угаданка 'ведьма, ясновидящее' является лексико-семантическое соответствие украинского языка, тождественное реконструированной форме и в плане морфологического строения (т.е. рефлексия модели девербативного строения слова) и в плане семантической: укр. угадник (вгадник) 'ясновидец' ↔ угадниця (вгадниия) 'т.ж. (ж.р.)' $\leftarrow$ гл. укр. угадуватися (вгадуватися) 'предвидеть, предчувствовать, быть суеверным; 2. предугадать, угадывать; 3. узнать' [ $\rightarrow$ укр. угадництво (вгадництво) 'умение угадывать'] [см. СУМ 371].

8 Об умении чёрта чародействовать, угадывать будущее подробнее см. Власова 2008: 538, 540; [особенно] 541, 544-545, 546-547.

9 Этимология этого слова до сих пор остаётся предметом дискуссии [подробнее см. Фасмер IV 377-378]. 
учитель 'Lehrer' (Смоленск) [СРНГ XII 252], русс. диал. начи́стка ↔ чистка 'чистка (помещения), Putzen' (басейн реки Дона) [CРНГ XII 289].

Основываясь на результатах морфологического анализа, можно выдвинуть предположение, что русс. диал. анчу́тка представляет собой образование из трёх структурных компонентов: преф. русс. на- + кор. русс. чуд- [с секундарным -m- (фонетическая запись) вместо этимологического -д-] + суфф. -ка $\rightarrow{ }^{*}$ начудка. Суффикс -ка в образованьях девербативов русского языка встречается весьма часто, ср. русс. пря́т-ка 'скрытие' $\leftarrow$ гл. русс. пря́тать 'спрятать, класть в сохранное место' [Даль III 534], русс. пряд-ка 'вытянутая изъ кудели и скрученная нить' $\leftarrow$ гл. русс. пряда́mь 'крутить нить изъ волоконъ, тянуть изъ чего и сучить нитку' [Даль III 533], русс. барабо́ш-ка 'безтолковый, суетливый, безпорядочный человек' $\leftarrow$ гл. русс. барабо́шить 'буторажить, суматошить и др.' [Даль I 47], русс. нахо́д-ка 'Fund' $\leftarrow$ гл. русс. находи́mь 'наталкиваться, натыкаться' [Даль II 491-492], русс. намо́лв-ка 'наговор, обвинение, навътъ' [Даль II 440; СРНГ XII 40] $\leftarrow$ гл. русс. намо́лвить, намолвля́ть 'насказывать, наговорить, клеветать' [Даль т.ж.] и др.

Имея в виду нейтральный семантический оттенок этих дериватов, можно с уверенностью утверждать, что с суфф. русс. -ка образуются не только диминутивы (ср. дистрибутивно вторичную семему русс. диал. анчу́тка 'чертёнок, бесёнок' (Саратов, Пенза, Рязань) [СРНГ I 262]) или пейоративы (по утверждению Топорова), но им также выражается дополнительная морфологическая дистрибуция субстантивизации, ср. русс. уга́dъ 465], русс. прядь ↔ прядка 'вытянутая изъ кудели и скрученная нить' [Даль III 533], русс. барабо́ша ↔ барабо́шка 'безтолковый, суетливый, безпорядочный человек' [Даль I 47], русс. нахо́дъ ↔ нахо́дка 'Fund' [Даль II 492] и др. значения данных примеров тождественны (!!!). Опираясь на эти данные, можно выдвинуть предположение о том, что русс. диал. анчу́m 'чёрт' $\leftrightarrow$ русс. диал. анчу́тка 'т.ж.' являются девербативами (или субстантивными дериватами) русского языка, означающими мифологические существа, вытворяющие необычайные вещи или явления, т.е. чертей.

Объяснение полисемии русс. диал. анчу́тка 'чёрт, дьявол, бес; антихрист; чертёнок, бесёнок; водяной чёрт; домовой; леший; неряха, грязнуля; бедный, несчастный человек; баловень, баловник; семема уничижительного значения ругательство' не представляется проблематичным, поскольку все перечисленные значения свойственны ими выражаемому референту - чёрту, в сознании людей имевшему антропоморфный облик рогатого, поросшего чёрною шкурой существа с копытами и хвостом [подробнее см. МС 595; Власова 2008: 533], которому свойственно было злиться [Власова 2008: 536], мстить [Власова 2008: 533], причинять вред [Власова 2008: 540-541], шутить и резвиться, а так же быть неопрятным и неаккуратным, неуклюжим [Власова 2008: 534-543, 546]. Возникновение семемы уничижительного значения - ругательства, видимо нужно связывать с привычкой чёрта появляться при произнесении его имени 
(см. выше), что было нежелательно. Значение 'бедный, несчастный человек' может интерпретироваться двояко: 1) как обозначение хитреца - эта черта характера особенно часто приписывается бесу; поэтому он зовётся лукавым [см. Власова 2008: 534] -, т.е. человека, который путём обмана [представляясь бедняком и занимаясь побирательством] хочет нажиться за счёт других; 2) образец семантического изменения, когда референт заменяется одним из его конотатов [подробнее см. Kregždys 2010: 24-26], в этом случае, принадлежностью дьяволу, т.е. приобретает значение злополучный человек (алкоголик [по данным русского фольклора, все пьяницы находятся во власти беса - Власова 2008: 542-543, 547], повесившийся или всякого рода самоубийца [см. Власова 2008: 543], чародей, умерший насильственной смертью [Власова 2008: 545], умерший или убитый некрещеный младенец [Власова 2008: 544] и др.) - все те, чьи души принадлежат дьяволу. Эта пенитентная зависимость понималась весьма занятно: все выше перечисленные, кроме детей [они в подземелье охраняли скарб чертей [Власова 2008: 544]], по русским поверьям, служили бесам средством перемещения, т.е. на них черти ездили верхом - этих горемык даже подковывали как лошадей [см. Власова 2008: 543].

Основываясь на выше изложенных аргументах, можно утверждать, что нет никаких причин русс. диал. анчу́тка сравнивать с названиями птиц водяного пространства и тем более объяснять его как балтизм - слово является исконно русским (!!!). В виду этого, установление возможных границ проживания протобалтийский племён на территории России, основываясь на ареальном распространении данной лексемы, не является возможным.

Выводы:

1) Русс. диал. анчýmка представляет собой девербатив, образованный из трёх структурных компонентов: преф. русс. на- + кор. русс. чуд- [с секундарным -m- (фонетическая запись) вместо этимологического - $\partial-]+$ суфф. -ка

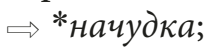

1a) форма *начудка подверглась морфотактической перестановки из-за феномена табу: *начуд-ка 'чёрт' > *анчуд-ка 'т.ж.' [морфологическая запись] $>$ русс. диал. анчým-ка 'т.ж.' [фонетическая запись];

16) русс. диал. анчу́тка является исконно русским словом, а не балтизмом;

2) русс. диал. анць́бб́́л является гибридным композитом из двух компонентов: греч. $\dot{\alpha} v \tau i-$ 'против' + ивр. -бул (сокращение [гипокористик] имени семитского бога Баал Зебуба[-була]);

3) полисемия русс. диал. анчýтка предопределена многообразием им выражаемого референта - чёрта. 


\section{ЛИТЕРАТУРА}

БТСРЯ - Большой толковый словарь русского языка, 2000, ред. С. А. Кузнецов, Санкт-Петербург.

Даль I-IV - Даль В., 1989-1991, Толковый словарь живого великорусского языка, т. 1-4, Москва.

МС - Мифологический словарь, 1990, Москва.

ПОС - Псковский областной словарь с историческими данными, 1989, т. 14, Ленинград.

САР - Словарь Академіи Россійской, 1794, т. 6, Санктпетербургъ.

СРНГ I-XLIII - Словарь русских народных говоров, 1965-2009, Ленинград (Санкт-Петербург).

СУМ - Словник української мови, 1979, т. 10, Київ.

Фасмер I-IV - Фасмер М., Этимологический словарь русского языка, 1986-1987, т. 1-4, Москва.

LE I-XXXVII - Lietuviu enciklopedija, 1953-1985, t. 1-37, Bostonas.

LKŽe - Lietuviu kalbos žodynas, 1956-1999, t. 1-20, Vilnius; доступ в интернете: www.lkz.lt RŽ - Religijotyros žodynas, 1991, Vilnius.

[другие сокращения как в LKŽe (см. www.lkz.lt/dzl.php?11)]

Аникин А. Е., 2000, Этимологический словарь русских диалектов Сибири, Москва-Новосибирск.

Власов а М., 2008, Энииклопедия русских суеверий, Санкт-Петербург.

Горя чев а Т. В., 2007, Восточнославянские этимологии, „Этимология 2003-2005”, Москва, с. 37-48.

Зализн як А. А., 1980, Грамматический словарь русского языка, Москва.

Лукашев ич П., 1846, ЧАРОМХТІЕ, или священный языкъ маговъ волхвовъ и жрецовъ, Петрьгородъ.

Топоров В. Н., 1973, Из истории балто-славянских языковых связей: анчу́тка, „Baltistica” IX (1), с. 29-44.

Топоров В. Н., 1975, Прусский язык: Словарь, т. 1, Москва.

Черкасов А. Т., Москвитина П. Д., 2005, Конь Рьжий: Сказания о людях тайги, Москва.

Шипов Е. Н., 1976, Словарь тюркизмов в русском языке, Алма-Ата.

Bus s ma n n H., 2006, Routledge Dictionary of Language and Linguistics, London-New York. Kregždys R., 2010, Baltų kalbų leksinès semantinès gretybès (paveldètieji ŏ/ā kamienų kūno daliu pavadinimai), Vilnius.

Lew is Ch. T., Short Ch., 1958, A Latin Dictionary Founded on Andrews' Edition of Freud's Latin Dictionary, Oxford.

Niermeyer J. F., 1976, Mediae Latinitatis lexicon minus, Leiden. 


\section{СОКРАЩЕНИЯ}

$\begin{array}{ll}\text { гл. } & - \text { глагол } \\ \text { ивр. } & - \text { иврит (еврейский язык) } \\ \text { позд. } & - \text { позднего периода } \\ \text { ср. } & - \text { сравните }\end{array}$

THE ETYMOLOGY OF THE RUSSIAN DIALECTAL LEXEME АНЧУTKA

\section{SUMMARY}

The article deals with the etymological analysis of Russ. dial. анчýmка 'devil, demon; Antichrist; hobgoblin, water-sprite, familiar, sylvan; trollop; poor person; pickle; curse'. The precondition is made, that it reflects multipartite derivative: prefix Russ. $\boldsymbol{H a -}+$ radix Russ. $4 y \partial$ - [with secondary $-m$ - (phonetic recording) instead

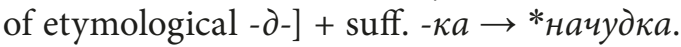

Being based on the made lexeme analysis, Russ. dial. анчýmка is explained as primordially Russian (!!!) word, which contrarily V. N. Toporov's hypothesis by no means could be compared with the water space birds names. Due to such decision it can not be explained as Baltism either. By virtue of it, determination of the Protobaltic tribes presumptive borders of their residing territory in Russia, according to areal distribution of the word, is not possible.

Key words: hypokoristic, hybrid composite, deverbativum, morphotactical rearrangement, phenomenon taboo.

Ключевые слова: гипокористик, гибридный композит, девербатив, морфотактическая перестановка, феномен табу. 